\title{
Wrist Septic Arthritis Due to Streptococcus pneumoniae Revealing a Selective Immunoglobulin G4 Subclass Deficiciency: A Case Report
}

\author{
Atchi Walla1 ${ }^{*}$, Anani Abalo1, Malewé Kolou² \\ ${ }^{1}$ Service de Chirurgie Orthopédique et Traumatologique, CHU Sylvanus Olympio, Lomé, Togo \\ ${ }^{2}$ Service d'Immuno-Hématologie, CHU Campus, Lomé, Togo \\ Email: *atchi.walla@yahoo.fr
}

Received 28 September 2015; accepted 2 November 2015; published 5 November 2015

Copyright (C) 2015 by authors and Scientific Research Publishing Inc.

This work is licensed under the Creative Commons Attribution International License (CC BY). http://creativecommons.org/licenses/by/4.0/

\section{(c) (i) Open Access}

\begin{abstract}
The pneumococcal septic arthritis is uncommon in healthy adults. In most cases, it occurs in patients with immune deficiency. Its exceptional location at the wrist can maintain doubt with rheumatic causes which are more frequent. IgG4 deficiency found in this patient was the only cause that could be impugned. We report the case of a young woman of 46 years without any evident cause of immunodeficiency and any particular risk factor, managed for septic arthritis of the wrist due to Streptococcus pneumoniae. This case without any apparent risk factors demonstrates that pneumococcal infection in a more distant articulation of the ENT is still possible. Scan has been a very significant contribution in confirming the positive diagnosis that leads to surgical drainage. The approach of the systematic search for the gateway must be done. In the study of the patient's immune status, the realization of the protein profile could be interesting and then guide the practitioner in the decision to vaccinate the patient against Streptococcus pneumoniae if he was not. We recommend looking always for a cause of immunodeficiency including primary Ig defiencies even among adult.
\end{abstract}

\section{Keywords}

Streptococcus pneumoniae, Septic Arthritis, Wrist, IgG4 Subclass Deficiency

\footnotetext{
${ }^{*}$ Corresponding author.
}

How to cite this paper: Walla, A., Abalo, A. and Kolou, M. (2015) Wrist Septic Arthritis Due to Streptococcus pneumoniae Revealing a Selective Immunoglobulin G4 Subclass Deficiciency: A Case Report. Open Journal of Orthopedics, 5, 350-354. http://dx.doi.org/10.4236/ojo.2015.511047 


\section{Introduction}

The pneumococcal septic arthritis is a disease of the elderly or weakened [1]-[4]. The literature shows that this organism is responsible for $3 \%$ to $10 \%$ of septic arthritis [2].

As in any septic arthritis, outcome may be severe or by direct systemic consequences of infection either by its local and regional extension. Mortality is not less than $10 \%$ and in more than half cases, it provides joint sequelae [5] [6].

Septic etiology in young adults appears not to be the first diagnostic hypothesis to which practitioners may think before when faced to patient with a painful wrist and fiver because rheumatic causes are far more frequent [7]. According to Dubost et al., staphylococci and streptococci Group B above are the main germs responsible of septic arthritis in the past three decades [8].

The poverty of the literature on the topic justified that we reported this case to highlight the unusual anatomical location and particularity of the affected patient.

\section{Case Report}

A woman of 46 years, a nursing assistant, consulted in February 2009 to the emergency ward of the hospital of Beauvais with pain, lameness and swelling on his right wrist started three days before (Figure 1). She had no particular medical history. A fever of $38^{\circ} \mathrm{C}$, and a pain in the overall mobilization of the wrist, was signs of clinical examination. There was no lymphadenopathy. Laboratory tests showed C Reactive Protein (CRP) at 304.5 $\mathrm{mg} / \mathrm{l}$, white blood cells (WBC) at 23,500 cells/ml and procalcitonin (PCT) at $2.94 \mu \mathrm{g} / \mathrm{l}$. Arthritis of the wrist hypothesis was raised and reinforced by the scanner which identified a joint effusion and the sheath of the extensors.

Surgical drainage by dorsal approach associated with a washing were made (Figure 2). The patient was put under probabilistic parenteral antibiotic therapy with amoxicillin-clavulanic acid. The wrist was immobilized in a splint plaster. Examination of wrist sample and blood cultures has identified a sensible pneumococcus. Antibiotic therapy combining $1 \mathrm{~g}$ of levofloxacin and $1.2 \mathrm{~g}$ of rifampin per day was instituted. The third postoperative day, the patient was afebrile (Figure 3 shows the appearance of the wrist at the third postoperative day). CRP, PCT and WBC were significantly regressed. In the second week, inflammation biomarkers were normalized and wrist gradually regained mobility with the gentle rehabilitation.

Meanwhile, the door of entry of the infection was investigated by X-rays of the lungs, sinuses, and cardiac ultrasound that have found anything. Serologies of human immunodeficiency virus (HIV), hepatitis B and C were negative.

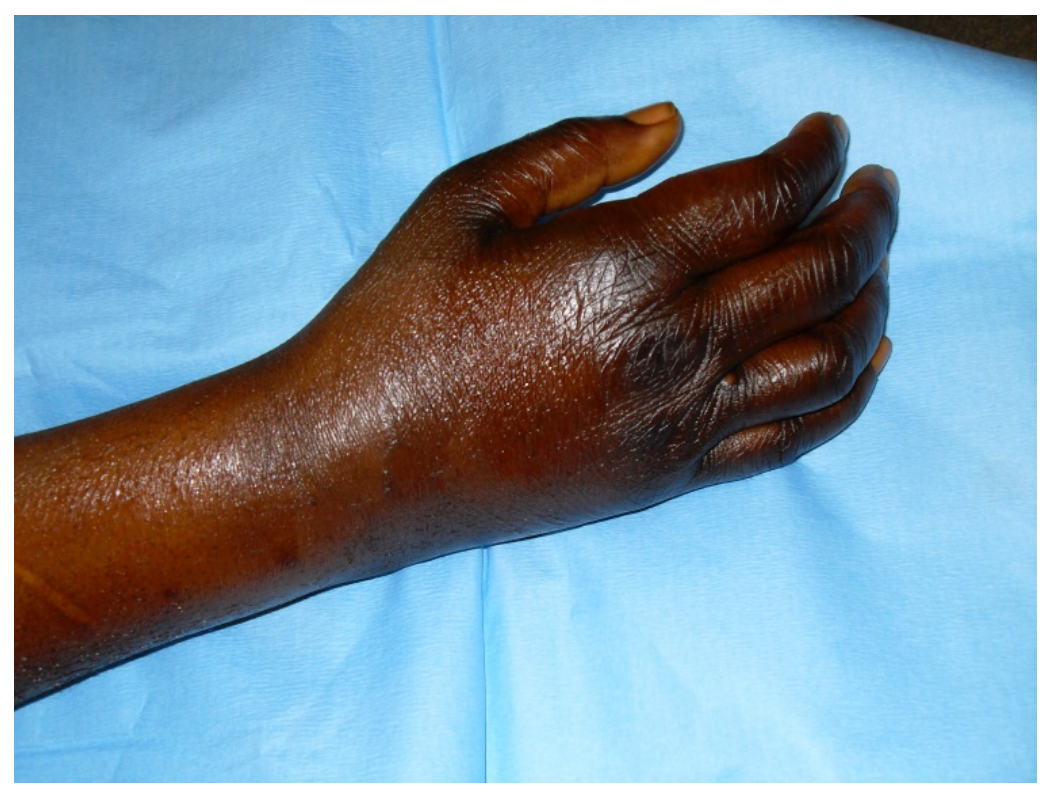

Figure 1. Wrist appearance during consultation. 


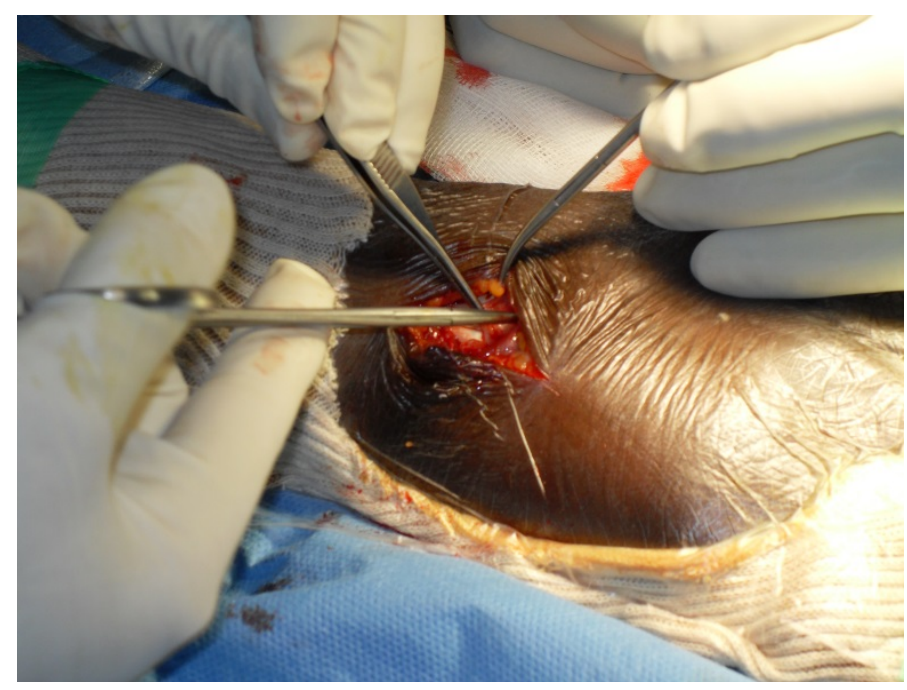

Figure 2. Dorsal view of wrist during drainage and washing.

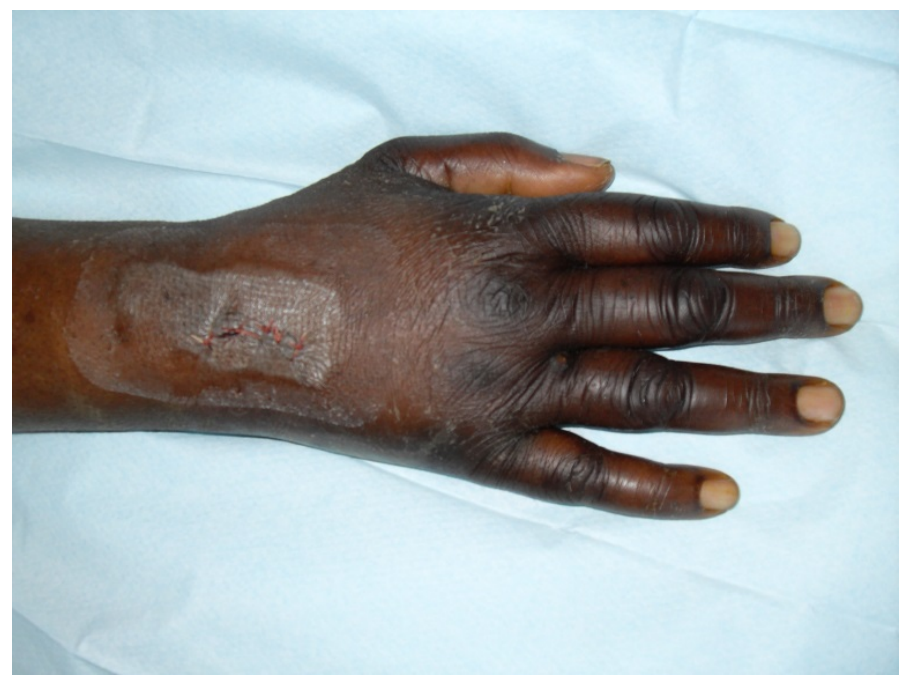

Figure 3. Wrist aspect at the third postoperative day.

Face scan had shown signs of left sphenoid sinusitis blowing the floor that did not require special treatment beyond that which had been established for joint infection. A protein profile that revealed a sharp decrease in immunoglobulin type G4. Antibiotic treatment was continued for six weeks and the patient vaccinated against pneumococcus. In the fourth month, the patient was asymptomatic, the biological balance and mobility of normal wrist.

\section{Discussion}

Streptococcus pneumoniae is responsible for septic arthritis in $3 \%$ to $10 \%$ and particularly affects peripheral joints of the child such as hip [2].

In healthy adults, bone and bone joint infections due to this organism are rare [3]. In most cases, these infections occur in subjects with risk factors; then it is subjects weakened by age and declining immune defenses. The infection of joints by pneumococcus is favored by the presence of factor inducing immunosuppression [9]. Most of these patients have at least one joint disease or underlying extra articular [4].

Among these co-morbidities, studies report the airway infections, heart disease, liver diseases, autoimmune diseases, hypertension, diabetes mellitus, chronic renal failure, malignancies, smoking regular, alcohol consumption, body mass index higher, the presence of prosthetic material, trauma [9]-[11]. Splenectomy, HIV in- 
fection, especially combined or humoral immunodeficiencies are also important risk factors [4] [9]. The most frequently affected joints are the knee, followed by the shoulder, elbow and hip occasionally [4] [12]-[15].

To our knowledge, the literature reports no cases of arthritis of the wrist due to this germ in adults without apparent risk factor.

In our patient, we believe that this bacterium is located encapsulated wrist hematogenously in favor of bacteremia caused by sinusitis. Opsonization is the phenomenon by which the encapsulated bacteria are phagocytosed and removed could not be effective because of the immunoglobulin deficiency of the patient; immunoglobulins $G$ are the most effective class of antibodies in the ospsonization [9]. It is a selective Immunodeficiency subclass (IgG4) immunoglobulin. In general, a selective deficit is congenital. In this context congenital, infectious order events related to that type of deficiency should occur at a younger age. This also supports the hypothesis that we issued earlier on professional risk factor for the caregiver.

Note that despite whether an adult, you have in the absence of a secondary immunodeficiency, primary immune deficiency look as is the case in our patient. The authors reported in 2013 the case of a woman of 59 years with a selective IgM deficiency who presented a septic arthritis due to pneumococcus [16].

In terms diagnosis, because of the frequency of rheumatic and causes reaction, septic origin is not necessarily the first case in front of a medical history without any particular patient with febrile wrist pain [11]. Even if the assertion of joint infection, pneumococcus is not the germ that can evoke in first intention.

As soon as septic arthritis is suspected, the puncture of the joint is imperative and urgent optionally by aid of a radiographic or sonographic identification [4]. However, the wrist joint cannot be easily punctured without local anesthesia, the risk of contact of lidocaine which is antibacterial with synovial can sterilize the sample [17]. Thus, in situations where the optimal conditions for joint aspiration are not met, the scan stills a very useful to the affirmation of positive diagnosis tool.

\section{Conclusion}

Our observation in a patient with no apparent risk factors demonstrates that pneumococcal infection in a more distant articulation of the ENT is still possible. Scan has been a very significant contribution in confirming the positive diagnosis that leads to surgical drainage.

The approach of the systematic search for the gateway must be done. In the study of the patient's immune status, the realization of the protein profile could be interesting and then guide the practitioner in the decision to vaccinate the patient against Streptococcus pneumoniae if he was not. We recommend looking always for a cause of immunodeficiency including primary Ig defiencies even among adult.

It would be valuable that future studies elucidate the exact role of immunoglobulin $G$ type 4 in pneumococcal infections.

\section{Conflict of Interest}

None.

\section{References}

[1] Dubost, J.J., Soubrier, M., De Champs, C., Ristori, J.M. and Sauvezie, B. (2004) Les arthrites septiques streptococciques de l'adulte: 55 cas et revue de la littérature. Revue du Rhumatisme, 71, 588-596. http://dx.doi.org/10.1016/S1169-8330(03)00303-X

[2] Forestier, E., Sordet, C., Cohen-Solal, J., Remy, V., Javier, R.M., et al. (2006) Bone and Joint Infection Due to Streptococcus pneumoniae in Two Immunocompetent Adults. Joint Bone Spine, 73, 325-328. http://dx.doi.org/10.1016/j.jbspin.2005.07.004

[3] Rossi, P., Granel, B., Mouly, P., Demoux, A.L., Le Mée, F., et al. (2010) An Atypical Pneumococcal Arthritis. BMJ Case Reports. http://dx.doi.org/10.1136/bcr.01.2010.2638

[4] Baraboutis, I. and Skoutelis, A. (2004) Streptococcus pneumoniae Septic Arthritis in Adults. Clinical Microbiology and Infection, 10, 1037-1039. http://dx.doi.org/10.1111/j.1469-0691.2004.00968.x

[5] Dubost, J.J. and Tournadre, A. (2006) Stratégie diagnostique des arthrites septiques à pyogènes des membres. Revue du Rhumatisme, 73, 114-153. http://dx.doi.org/10.1016/j.rhum.2005.12.003

[6] Meier, R. and Lanz, U. (2007) Septic Arthritis of the Wrist. Handchirurgie, Mikrochirurgie, Plastische Chirurgie, 39, 112-117. http://dx.doi.org/10.1055/s-2007-964876 
[7] Arsene, C., Saste, A., Somiah, M., Mestrovich, J. and Berger, G.A. (2014) Case of Septic Arthritis of the Wrist Due to Finegoldia Magna. Case Reports in Infectious Diseases, 2014, Article ID: 793053. http://dx.doi.org/10.1155/2014/793053

[8] Dubost, J.J., Couderc, M., Tatar, Z., Tournadre, A., Lopez, J., Mathieu, S. and Soubrier, M. (2014) Évolution sur 30 ans de la répartition des germes responsables d'arthrite septique sur articulation naïve. Étude monocentrique de 374 cas. Revue du Rhumatisme, 81, 495-497. http://dx.doi.org/10.1016/j.rhum.2014.04.003

[9] Martinot, M., Oswald, L., Parisi, E., Etienne, E., Argy, N., et al. (2014) Immunoglobulin Deficiency in Patients with Streptococcus pneumoniae or Haemophilus Influenzae Invasive Infections. International Journal of Infectious Diseases, 19, 79-84. http://dx.doi.org/10.1016/j.ijid.2013.10.020

[10] Bertani, A., Drouin, C., Demortière, E., Gonzalez, J.F., Candoni, P., et al. (2006) A Prosthetic Joint Infection Caused by Streptococcus pneumoniae: A Case Report and Review of the Literature. Revue de Chirurgie Orthopedique et Reparatrice de l'Appareil Moteur, 92, 610-614. http://dx.doi.org/10.1016/S0035-1040(06)75921-9

[11] Rashkoff, E.S., Burkhalter, W.E. and Mann, R.J. (1983) Septic Arthritis of the Wrist. Journal of Bone \& Joint Surgery (American Volume), 65, 824-828.

[12] Ispahani, P., Weston, V.C., Turner, D.P.J. and Donald, F.E. (1999) Septic Arthritis Due to Streptococcus pneumoniae in Nottingham, United Kingdom, 1985-1998. Clinical Infectious Diseases, 29, 1450-1454. http://dx.doi.org/10.1086/313526

[13] James, P.A. and Thomas, M.G. (2000) Streptococcus pneumoniae Septic Arthritis in Adults. Scandinavian Journal of Infectious Diseases, 32, 491-494. http://dx.doi.org/10.1080/003655400458758

[14] Ross, J.J., Saltzman, C.L., Carling, P. and Shapiro, D.S. (2003) Pneumococcal Septic Arthritis: Review of 190 Cases. Clinical Infectious Diseases, 36, 319-327. http://dx.doi.org/10.1086/345954

[15] Kauffman, C.A., Watanakunakorn, C. and Phair, J.P. (1976) Pneumococcal Arthritis. Journal of Rheumatology, 3, 409-419.

[16] Phuphuakrat, A., Ngamjanyaporn, P., Nantiruj, K., Luangwedchakarn, V. and Malathum, K. (2013) Selective IgM Deficiency in an Adult Presenting with Streptococcus pneumoniae Septic Arthritis. Journal of Microbiology, Immunology and Infection. http://dx.doi.org/10.1016/j.jmii.2013.01.009

[17] Dory, M.A. and Wautelet, M.J. (1985) Arthroscopy in Septic Arthritis. Lidocaine- and Iodine-Containing Contrast Media Are Bacteriostatic. Arthritis \& Rheumatology, 28, 198-203. http://dx.doi.org/10.1002/art.1780280215 